\title{
INCLUSIÓN Y ORIGEN GEOGRÁFICO LA ALTA FUNCIÓN PÚBLICA DEL ESTADO ESPAÑOL
}

\author{
Jorge Crespo GonzÁlez \\ Instituto Complutense de Ciencias de la Administración \\ Universidad Complutense de Madrid, España \\ jorge.crespo@cps.ucm.es
}

\section{RESUMEN}

El presente artículo analiza el origen geográfico de los miembros de la alta función pública del Estado español, a partir de un estudio del Cuerpo Superior de Administradores Civiles del Estado. Se presenta un análisis diacrónico del origen geográfico de sus miembros (incluyendo asimismo algunos datos del cuerpo diplomático). Los resultados obtenidos son puestos en relación con el trabajo empírico realizado, extrayéndose conclusiones de interés sobre las causas de la sobre e infra-representación de los integrantes de dicho cuerpo nacidos en unas CCAA respecto de otras. Finalmente, se incluye un catálogo de fórmulas para mejorar la representatividad autonómica de la AGE y se muestra la potencia de la movilidad interadministrativa desde una perspectiva intergubernamental, con vistas a obtener una función pública más inclusiva.

Palabras clave: Élites, Origen geográfico, Alta función pública, Inclusión, Gobernanza, España. 


\section{INCLUSION AND GEOGRAPHICAL ORIGIN OF SENIOR CIVIL SERVANTS IN SPAIN}

\section{ABSTRACT}

This article analyzes the geographical origin of senior civil servants in Spain, based on a study of the Upper Body of Civil State Administrators. A diachronic analysis of the geographical origin of its members (including some data for the diplomatic service) is presented. The results obtained are combined with the empirical work carried out, drawing interesting conclusions about the causes of the over- and under-representation of the members of this body who were born in some autonomous communities as opposed to others. Finally, the article includes a catalog of formulas to improve the regional representativeness of the General State Administration (AGE) and shows the power of inter-administrative mobility from an intergovernmental perspective, with a view to achieving a more inclusive civil service.

Keywords: Elites, Geographical origin, Senior civil service, Inclusion, Governance, Spain. 


\section{INTRODUCCIÓN}

En este artículo se pretende realizar un estudio sobre el origen geográfico de los funcionarios de la Administración General del Estado (AGE), focalizando la unidad de análisis en el cuerpo superior de administradores civiles del Estado, y orientando la reflexión a considerar si dicho origen tiene relevancia en términos de inclusividad y de cohesión del Estado español.

El análisis se inscribe en el marco de los estudios intergubernamentales o de la gobernanza multinivel, los cuales han incorporado recientemente la variable inclusiva al análisis. Una hipótesis que se desea abordar es si la descentralización política que ha experimentado el Estado español desde 1978 ha supuesto un cambio en la procedencia de las élites funcionariales de la AGE.

En el artículo se explotarán, junto a otras fuentes, los datos empíricos de una investigación reciente que el autor ha realizado sobre el origen y perfil intergubernamental de los altos funcionarios españoles, centrada esencialmente en el ya citado cuerpo de Administradores Civiles del Estado $^{1}$ (ACE). También, aunque con un menor nivel de detalle, se incluirán algunos datos extraídos sobre los diplomáticos españoles, a partir del análisis de la procedencia geográfica de aquellos que disponen de la categoría de embajadores y son jefes de embajada a julio de 2019 (126 efectivos).

El documento está estructurado en las siguientes partes. En primer lugar, y para centrar el debate teórico, se alude a los estudios intergubernamentales, su origen, pautas principales de análisis (entre las que destaca el interés por el factor humano) y los autores más importantes que lo han tratado. Posteriormente, se precisa qué se entiende por alta función pública, realzando el interés del cuerpo de Administradores Civiles del Estado. A continuación, se concretará la importancia de los ACE desde una perspectiva funcional, como paso previo para realizar un análisis diacrónico del origen geográfico de sus miembros (incluyendo asimismo algunos datos del cuerpo diplomático). Los resultados obtenidos son puestos en relación con el trabajo empírico realizado, extrayéndose conclusiones de interés sobre las causas de la sobre e infrarrepresentación de los integrantes de dicho cuerpo nacidos en unas comunidades autónomas respecto de

1 El trabajo empírico incorporó la respuesta a un cuestionario de 102 de sus miembros y la realización de múltiples entrevistas a académicos de la talla de Sabino Cassese, Manuel Arenilla o Mariano Baena del Alcázar. La fase de obtención de datos finalizó a principios de 2017 y debemos agradecer la colaboración de la Asociación Profesional del Cuerpo Superior de Administradores Civiles del Estado y del Instituto Nacional de Administración Pública de España. 
otras. Finalmente, se incluye un catálogo de fórmulas para mejorar la representatividad autonómica de la AGE y se muestra la potencia de la movilidad interadministrativa desde una perspectiva intergubernamental.

\section{LOS ESTUDIOS SOBRE FUNCIÓN PÚBLICA VISTOS DESDE UNA PERSPECTIVA INTERGUBERNAMENTAL}

Los estudios intergubernamentales surgen en el marco del federalismo estadounidense de los años treinta del siglo XX, y desde entonces han tenido un amplio desarrollo en aquel país y en otros estados que cuentan con una fuerte descentralización política del poder. Se caracterizan dichos estudios, sin menospreciar los aspectos normativos dentro de una metodología multidisciplinar, por dar una gran relevancia al análisis del funcionamiento práctico de los estados, deteniendo su estudio en la pluralidad de actores que intervienen en las políticas públicas y la interdependencia con que actúan, y no tanto en las distinciones formales que el Derecho Público viene realizando entre estados unitarios y federales. Son varios los autores que han descrito y analizado la importancia de aspectos orgánicos (consejos e instituciones de cooperación, coordinación y colaboración), para el gobierno multinivel de los estados, destacando el reciente estudio de Schnabel (2020), pero en general se echa en falta un análisis más profundo del factor humano que interviene en las reuniones de esos órganos.

En ese contexto, los autores pioneros en este marco analítico (por ejemplo, Anderson 1960) se plantearon un conjunto de pautas de análisis (la participación fluida y multinivel, la importancia de los aspectos financieros $y$ de las subvenciones intergubernamentales, etc.) que incorporaban en un lugar preeminente el factor humano como decisivo en las redes de actores, lo que ha venido repitiéndose por los principales investigadores sin descanso desde entonces (por ejemplo, Wright 1997, 1978, Agranoff 1997, 1991, Peters 2008). Y dentro de ese factor humano, que en el caso americano incluye de manera amplia al personal electo y profesional, no cabe duda que la alta función pública tiene una gran relevancia, aunque los estudios empíricos realizados sobre ella sean escasos y fragmentarios (Cho 2007: 51).

Otro estudioso de la importancia de la función pública a nivel intergubernamental es Parry (2004), quien analiza el Civil Service británico, y que plantea una muy interesante conclusión: que la alta función pública es un factor que puede potencialmente favorecer unas buenas relaciones intergubernamentales en Reino Unido, pues incorpora funcioneslubricantes y adhesivas sobre el sistema político-administrativo (Parry 2012). A este aspecto, sin duda, podría añadirse el argumento proporcionado por Stein 
(1984) al apuntar que las relaciones intergubernamentales y el gobierno mejorarían si se impulsaran carreras multinivel para los empleados públicos. Un planteamiento complementario es el de Verkuil (2015), que la visualiza como una infraestructura humana que permite a las sociedades reaccionar ante situaciones críticas con una mejor y mayor resiliencia, lo que nos permite interrogarnos sobre la manera en qué dicha función pública se cohesiona internamente y se adapta externamente al contexto, cuestiones para las cuales la inclusividad es un aspecto determinante.

En el caso español, sumido en un proceso federalizante en la práctica con independencia de lo que explicite la normativa, en los últimos años han prodigado estudios que toman el marco analítico de las relaciones intergubernamentales como referente, destacando autores como Colino (2012), Arbós et al. (2009) u otros, pero sin embargo el tratamiento dado a la función pública ha sido prácticamente inexistente o muy insuficiente (una excepción notable puede hallarse en Del Pino y Colino 2021). Se ha puesto el interés en otros aspectos: articulación normativa de las competencias, instrumentos orgánicos y formales de cooperación, la disfuncionalidad del Senado, algunos actores clave tales como los partidos políticos y el Tribunal Constitucional, etc. Pero, sin embargo, no ha existido una línea de análisis intergubernamental sobre la función pública, en los términos que aquí se proponen, que dé respuesta adecuada a las siguientes preguntas o interrogantes que aborda nuestra investigación, en el contexto politológico de los estudios de la Ciencia de la Administración e incorporando como instrumental analítico el proporcionado por las relaciones intergubernamentales.

\section{EL CUERPO SUPERIOR DE ADMINISTRADORES CIVILES DEL ESTADO COMO EXPONENTE DE LA ALTA FUNCIÓN PÚBLICA ESPAÑOLA}

En este documento se mantiene una vinculación o identificación de la función pública en sentido restringido con los grupos burocráticos o alta función pública. Esto se justificaría por la especial y directa relación que sus funciones tienen respecto de los fines del Estado, su alta especialización y profesionalización y el requisito de titulación universitaria superior para su acceso. Es decir, competencia y profesionalización, permanencia protegida en el empleo público como garantía de imparcialidad y neutralidad, capacidad para frenar decisiones (veto decisorio) u obstaculizar la aplicación de las políticas (veto paralizante) y disponer como instrumentos de poder, además de la estabilidad en el empleo y su posición jerárquica, su influencia en la legislación, el control de los recursos y la cercanía con el poder decisorio público y privado (Baena 1988: 440-445), son notas 
específicas del concepto de alta función pública que se mantiene en este trabajo. Este concepto de alta función pública implica no incluir en el mismo los empleados públicos profesionales que no ejercen al máximo nivel el poder administrativo, los contratados laborales y el personal político o de designación política en tanto tal; lo que no significa desconocer que son frecuentes los casos en que altos funcionarios ocupan temporalmente puestos políticos, pero a nosotros nos interesan en tanto altos funcionarios y no en tanto políticos temporales.

Eso expresado, es necesario acotar más el perímetro del análisis. A pesar de que se defiende la existencia de altos funcionarios en las diferentes administraciones públicas españolas, y entre ellas en las territoriales (AGE, comunidades autónomas y entes locales), nuestro estudio se focalizará en la alta función pública de la AGE y, dentro de ella, en el Cuerpo Superior de Administraciones Civiles del Estado. Ello no implica que no se reconozca, como se ha escrito, el interés e importancia de estudiar las altas funciones públicas autonómicas o locales, o analizar dentro de la AGE otros cuerpos con gran proyección estratégica (por ejemplo, el de Abogados del Estado, Cuerpo Diplomático, Economistas del Estado, alta función pública militar, etc.) o incluso los que les auxilian directamente en sus labores (cuerpos del grupo $\mathrm{B}$ en la denominación pre-EBEP [Estatuto Básico del Empleado Público] o grupo A2 del EBEP), etc. Además de por lógicas razones de economía y eficacia, hemos decidido centrarnos en la alta función pública de la AGE por la posición estratégica e integrada que dicha administración tiene sobre el conjunto del Estado, por sus relaciones con el resto de las administraciones territoriales, y por su posición privilegiada en la configuración y participación en el marco de los órganos de coordinación, cooperación y colaboración con las comunidades autónomas. Precisamente el traspaso de gran parte de los servicios prestaciones a las comunidades autónomas ha permitido, y en cierto modo obligado, un proceso que todavía no ha finalizado, que ha hecho que la AGE haya tenido que reinventarse centrándose en las funciones estratégicas y relacionales indispensables para la supervivencia del sistema, así como para contribuir a garantizar la participación de los diferentes intereses en la construcción del interés general.

Como hemos indicado en otro lugar (Crespo 2017), dentro de esta función pública de alto nivel y con funciones estratégicas destaca el Cuerpo Superior de Administradores Civiles del Estado, el cual se caracteriza por su carácter generalista, transversal y predirectivo y directivo, y sus importantes funciones en la gestión de las políticas públicas y gestión de recursos comunes de los departamentos ministeriales. En palabras de algunos de sus miembros, el cuerpo de ACE es un "cuerpo generalista especializado en 
estrategia, planificación y dirección”, o un "cuerpo especialista en lo general y en políticas transversales", o un "cuerpo con una orientación profesional generalista y una visión integradora de la administración pública”, al que se le reconoce liderazgo en la adaptación al cambio y por su orientación hacia la innovación (citas extraídas de AAVV 2014).

Por esas funciones transversales y su apoyo al proceso de decisiones y a los órganos de cooperación entre Estado y comunidades autónomas, dicho cuerpo constituye una buena atalaya para avizorar cómo se produce la coordinación en el Estado español, y conocer las actitudes e imágenes que sus integrantes tienen sobre el funcionamiento del Estado autonómico. Lo anterior le configura como un actor indispensable para, entre otros aspectos, diagnosticar la situación de la coordinación, los aspectos mejorables de la misma, o los roles y perfil de competencias que deben atesorar los altos funcionarios para adaptarse a una situación de gobernanza compleja con múltiples actores intervinientes de diferentes niveles de gobierno.

El autor participa de otro criterio adicional, compartido con Baena, respecto de la importancia del Cuerpo Superior de Administradores Civiles del Estado, en tanto cuerpo principal que ejerce funciones de administración general con una fuerte proyección multinivel:

Esto es muy importante: la Administración general es más decisiva que la especial, ya que sin ella no habría realmente Administración (ni Ciencia de la Administración). Efectivamente, es la que incorpora e integra funciones y dirige unidades administrativas de gestión económica, jefaturas de personal con sus ramificaciones, elabora presupuestos en colaboración con hacienda, y se encarga del diseño organizativo donde los aspectos intergubernamentales tienen importancia. Finalmente, debe precisarse que estas funciones son el cerebro y el corazón de la Ciencia de la Administración, y que sin ellas no existiría, sino solo un grupo de especialistas al servicio de la Administración. Una administración sin administración general no existe como tal (Entrevista Baena).

Una vez establecido qué se entiende por alta función pública, y explicada la motivación de la selección del cuerpo de ACE a efectos de extracción de información, cumple detenerse en las funciones que estos funcionarios desarrollan a nivel intergubernamental. Con ello entramos ya de lleno en la explotación del trabajo empírico practicado en la investigación. 


\section{LAS FUNCIONES DE LOS ACE EN PERSPECTIVA INTERGUBERNAMENTAL}

Primeramente, y antes de caracterizar las principales funciones de los ACE desde el punto de vista intergubernamental, se les interrogó por su percepción del grado en que dicho colectivo colabora funcionalmente, junto a los políticos, en la confección de las decisiones públicas y, asimismo, en la implantación de las decisiones públicas con impacto autonómico (ver Gráfico 1). Respecto de lo primero, se trataba de constatar la medida en que los ACE intervienen en lo que Baena (1988: 441) denomina "veto decisorio" de la burocracia; y respecto de lo segundo, en lo que el mismo califica como "veto paralizante" o ejecutorio.

Gráfico 1: Participación de los ACE en las políticas públicas multinivel

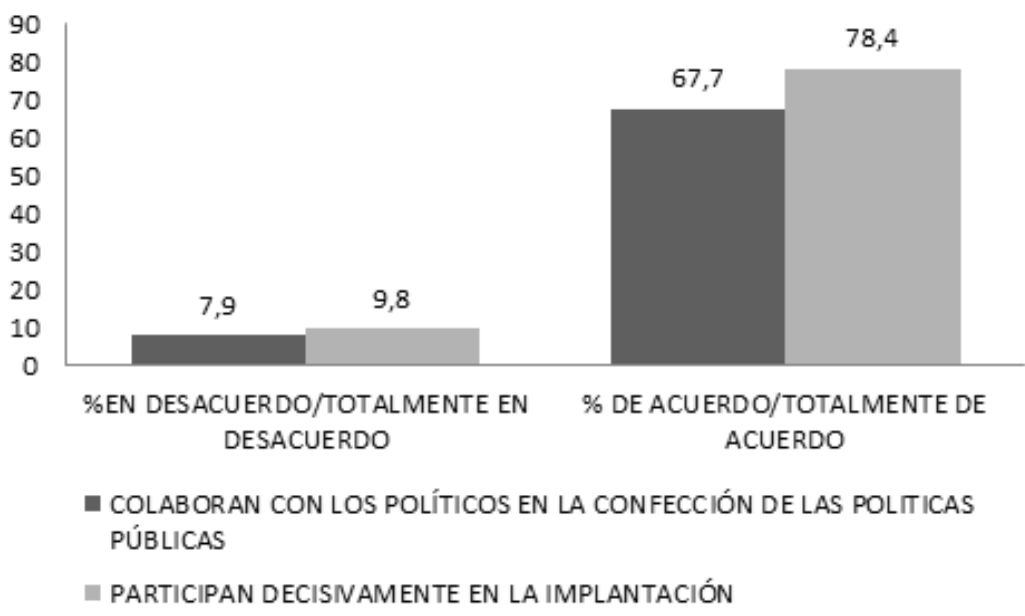

Fuente: Elaboración propia.

Respecto de su participación en la confección de decisiones, los datos plantean que los ACE respaldan la afirmación de que los mismos colaboran decisivamente con los políticos en la confección de las decisiones públicas con incidencia autonómica $(67,7 \%$ de acuerdo y totalmente de acuerdo, frente al 7,9\% en desacuerdo y totalmente en desacuerdo $)^{2}$.

Algo similar puede establecerse respecto de la afirmación relativa a que las funciones de los ACE son decisivamente necesarias para implantar decisiones públicas del Estado con repercusión autonómica (78,4\% versus $9,8 \%)$.

2 En lo sucesivo para favorecer la comparación se opta por presentar los datos agrupados de las respuestas "De acuerdo y totalmente de acuerdo" versus "En desacuerdo y totalmente en desacuerdo", no citándose las indiferentes. 
Tabla 1: Roles que se concretan en el ejercicio profesional de los ACE. Porcentajes

Roles

El rol técnico de expertos que ejercen una competencia

89,2

El rol de patrocinio de intereses

El rol de agente (broker), que negocia intereses diferentes

$\mathrm{El}$ rol de facilitadores, que median entre intereses de grupos

El rol partidista, que defiende una posición política bien clara

El rol de ideadores y formuladores de nuevos programas

El rol de garante de la imparcialidad del Estado

El rol de expertos legales

El rol de defensor cívico que protege los derechos de la colectividad

Otro

Elaboración propia a partir de Aberbach, Putnam y Rockman (1981).

Una vez destacada la importancia de las funciones de los ACE con implicaciones autonómicas, el foco se puso en los roles que, de acuerdo con su experiencia, pueden adoptar los altos funcionarios en un escenario multinivel (ver Tabla 1). La pregunta se inspiraba en el estudio clásico realizado por Aberbach, Putnam y Rockman (1981), que mediante un examen comparado entre seis países (Estados Unidos, Reino Unido, Alemania, Países Bajos, Francia e Italia), puso en evidencia, entre otros aspectos, los diferentes roles político-administrativos que intervienen en los procesos decisorios. La aplicación de los diversos roles confeccionados en la investigación de Aberbach, Putnam y Rockman (1981) al colectivo de los ACE concretó que los principales con los que se identifican son los siguientes: el de técnico que ejerce una competencia (89,2\%); el de garante de la imparcialidad del Estado (87,3\%); el de ideadores y formuladores de nuevos programas $(71,6 \%)$ y el de expertos legales $(68,6 \%)$. Sin embargo, los que cuentan con menor apoyo son aquellos que implican una adopción partidaria o de interés a instancia de parte, quedando claramente establecido su falta de apoyo, por ejemplo, al rol partidista $(2,9 \%)$, al de patrocinio de intereses $(5,9 \%)$ y al de broker, que negocia intereses diferentes (15,7\%). Lo que significa que el colectivo estudiado interpreta sus expectativas de actuación en términos ligados a la competencia técnica y jurídica, pero también respecto de los valores básicos del servicio público (neutralidad e imparcialidad), sin despreciar aspectos creativos (rol de ideadores y formuladores) junto a los que facilitan la interacción (facilitadores y mediadores). 


\title{
LA PROCEDENCIA GEOGRÁFICA DE LOS ACE Y SU SIGNIFICACIÓN EN TÉRMINOS PARA LA CONSTRUCCIÓN DE UN ESTADO INCLUSIVO
}

\author{
DiAgNósTiCO: DATOS SOBRE EL ORIGEN GEOGRÁFICO EN LA ALTA \\ FUNCIÓN PÚBLICA A TRAVÉS DE LOS ACE y DE LOS EMBAJADORES DE \\ España (JEFEs de EMbajada ante Estados)
}

Recientes investigaciones empíricas sobre la alta función pública del Estado (una dirigida por Ruano de la Fuente 2014, Crespo 2015a, 2015b, 2015c, 2017, y dos apoyadas por el Instituto Nacional de Administración Pública), analizaron la procedencia geográfica de los miembros del Cuerpo Superior de Administradores Civiles del Estado y de la Carrera Diplomática (embajadores en ejercicio en 2015 y 2019), y muestran una realidad paradójica: a pesar de la transición política y de la fuerte descentralización del poder realizado en los últimos decenios a favor de las comunidades autónomas, importantes cuerpos de la Administración General del Estado se nutren de candidatos procedentes en buena medida de las regiones geográficas centrales del país (destacando notoriamente la de Madrid, con una representación tres veces superior a la que le correspondería por peso demográfico) y no tanto de algunas regiones muy relevantes en términos demográficos y culturales (significándose claramente el caso deficitario de Cataluña).

Crespo (2015c) asume la importancia de considerar la administración pública como un espejo de la sociedad a la que sirve, y en la que, por lo tanto, desde una perspectiva institucional, debería incluirse la diversidad y complejidad de la ciudadanía. El interés del asunto no es menor, como ya ha sido señalado, "dada la relevancia de la alta función pública para la conformación de la cultura político-administrativa, para la conformación del liderazgo político, por un peso histórico que traspasa etapas y gobiernos" (Entrevista Arenilla) y por la constatación de que de la alta función pública se nutren las élites públicas y privadas del país (Entrevista Baena).

En efecto, respecto de los ACE (denominación actual de los antiguos técnicos de administración civil), el análisis diacrónico de la investigación publicada por Julián Álvarez (1980) respecto de la dirigida por Ruano (2014) (véase Tabla 2) destaca la persistencia de la fuerte sobrerrepresentación de la región madrileña, así como de Castilla y León, y la mejora en la representación de Galicia, Asturias y Aragón. Sin embargo, sorprende entre las comunidades autónomas infrarrepresentadas que Cataluña, partiendo de una base débil en los años sesenta y setenta (apenas un 22\% de las plazas que le corresponderían por peso demográfico se cubre por candidatos 
nacidos en Cataluña), no solo no ha mejorado, sino todo lo contrario a lo largo del tiempo. Lo mismo puede decirse de Extremadura y Navarra.

Tabla 2: Índice de proporcionalidad del origen geográfico de los TAC/ACE, 1960-2011

\begin{tabular}{|c|c|c|c|}
\hline Comunidad autónoma & $\begin{array}{c}\text { TAC/ACE } \\
1960-1977\end{array}$ & $\begin{array}{l}\text { TAC/ACE } \\
2007-2011\end{array}$ & $\begin{array}{c}\text { Personal en } \\
\text { formación } \\
2013\end{array}$ \\
\hline Andalucía & 89 & 118,43 & 22,45 \\
\hline Aragón & 83 & 906,25 & 117,60 \\
\hline Asturias, principado & 47 & 0 & 146,2 \\
\hline Balears, Illes & 48 & 0 & 298,35 \\
\hline Canarias & 57 & 0 & 0 \\
\hline Cantabria & - & 0 & 545,19 \\
\hline Castilla y León & - & 96,26 & 187,07 \\
\hline Castilla-La Mancha & 70 & 0 & 76,07 \\
\hline Cataluña & 22 & 0 & 0 \\
\hline Comunitat Valenciana & 76 & 0 & 0 \\
\hline Extremdura & 70 & 0 & 0 \\
\hline Galicia & 78 & 88,48 & 115,19 \\
\hline Madrid, comunidad & 433 & 192,32 & 327,61 \\
\hline Murcia, región & 61 & 0 & 109,05 \\
\hline Navarra, cdad foral & 126 & 0 & 0 \\
\hline País Vasco/Vascongadas & 89 & 112,63 & 0 \\
\hline Rioja & - & 0 & 0 \\
\hline Ceuta & - & 0 & 2235,46 \\
\hline Melilla & - & 0 & 2092,63 \\
\hline
\end{tabular}

Nota: El indice de proporcionalidad es igual al porcentaje de TAC/ACE originarios de la respectiva comunidad/porcentaje demográfico de la comunidad en el Estado* 100

Para 1960-1977, se utilizaron los datos de Álvarez (1980). La fuente para el periodo 2007-2011 y 2013 es Ruano (2014), al igual que para el personal en formación en el Instituto Nacional de Administración

Pública en 2013. Fuente: Crespo (2015c).

En lo que concierne a la Carrera Diplomática, en el estudio se toman como datos iniciales los publicados por Rocío Valdivielso (1996) y son comparados con los obtenidos en 2015 y 2019 para el colectivo de embajadores en ejercicio en estados (poco más de 120 personas), 
excluyendo las organizaciones internacionales (ver Gráfico 2). De nuevo, la fuerte sobrerrepresentación histórica de la Comunidad de Madrid (más que triplica el número de embajadores que le corresponderían por peso demográfico) no solo no se ha reducido, sino que se ha ampliado; Baleares y Asturias, que partían de una representación equilibrada en 1991, se orientan hacia una sobrerrepresentación en 2015; y el País Vasco se encuentra en términos de equilibrio en las dos fechas. Cataluña, Comunidad Valenciana, Extremadura, acompañadas esta vez por Galicia y Canarias, aparecen como casos preocupantes de infrarrepresentación. Los resultados para este colectivo en general no han mejorado en 2019, pues el análisis del origen de los 126 embajadores estudiados, que ejercen la jefatura de embajadas, produce resultados similares a los obtenidos en 2015 (véase Tabla 3).

Gráfico 2: Índice proporcionalidad personal diplomático en 1991 y 2015

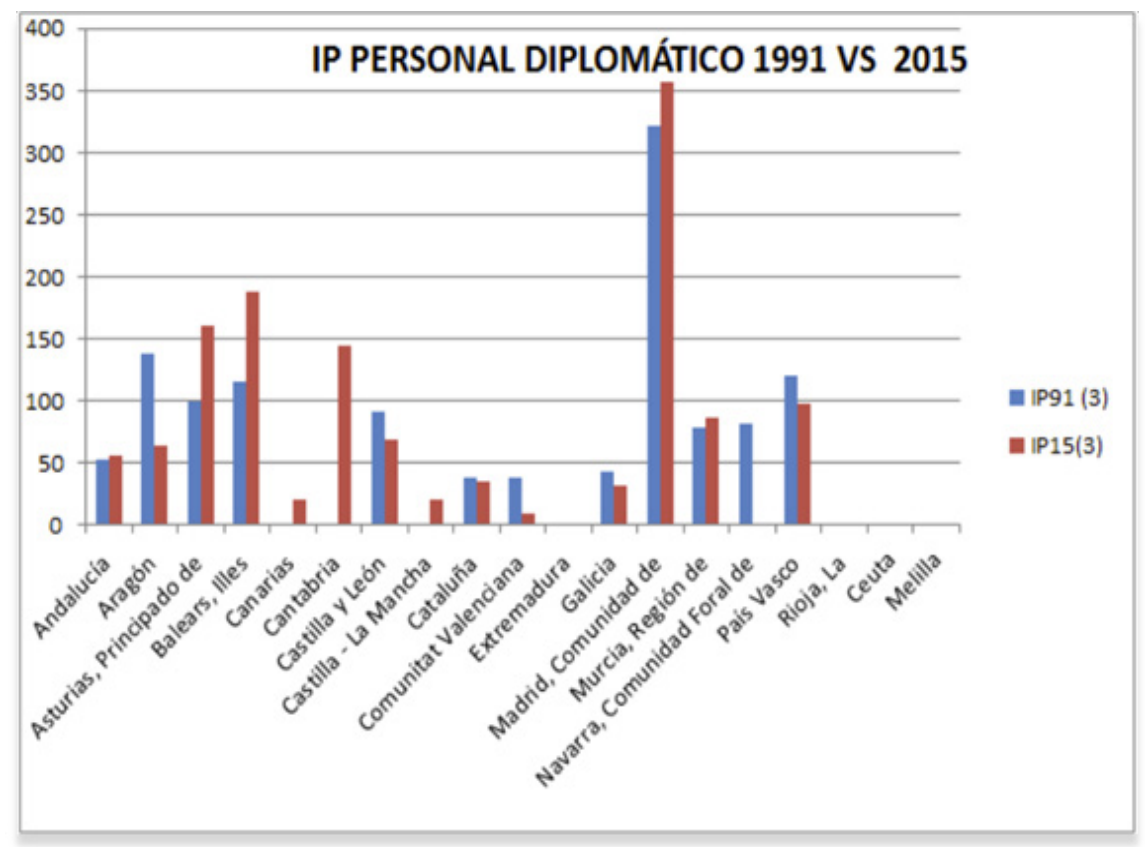

* Las comunidades autónomas con una proporción inferior al $1 \%$ del total de diplomáticos no aparecen registradas en los datos proporcionados por Valdivieso (1996). **IP 91: indice de proporcionalidad (igual a porcentaje de diplomáticos originarios de una comunidad dividido por porcentaje de peso demográfico de una comunidad respecto del Estado multiplicado por

Fuente: Crespo (2015c). 
Tabla 3: Embajadores por comunidad autónoma de origen, con datos de población (2019)

\begin{tabular}{|c|c|c|c|}
\hline Comunidad & Población & Embajadores & $\begin{array}{c}\text { Por peso } \\
\text { demográfico }\end{array}$ \\
\hline
\end{tabular}

\begin{tabular}{|c|c|c|c|c|}
\hline Andalucía & 8.405 .294 & 15 & 21 & -6 \\
\hline Aragón & 1.316 .064 & 7 & 3 & +4 \\
\hline Asturias & 1.024 .381 & 3 & 2 & +1 \\
\hline Cantabria & 580.997 & 2 & 1 & +1 \\
\hline Ceuta & 84.913 & 0 & 0 & - \\
\hline $\begin{array}{l}\text { Castilla y } \\
\text { León }\end{array}$ & 2.410 .819 & 6 & 6 & - \\
\hline $\begin{array}{l}\text { Castilla-La } \\
\text { Mancha }\end{array}$ & 2.030 .807 & 0 & 5 & -5 \\
\hline Canarias & 2.188 .626 & 2 & 5 & -3 \\
\hline Cataluña & 7.516 .544 & 10 & 19 & -9 \\
\hline Extremadura & 1.067 .272 & 0 & 2 & -2 \\
\hline Galicia & 2.699 .299 & 5 & 6 & - \\
\hline Islas Baleares & 1.176 .627 & 3 & 3 & - \\
\hline Murcia & 1.479 .098 & 0 & 3 & -3 \\
\hline Madrid & 6.587 .711 & 44 & 17 & +27 \\
\hline Melilla & 84.667 & 1 & 0 & +1 \\
\hline Navarra & 646.197 & 0 & 1 & -1 \\
\hline País Vasco & 2.172 .591 & 7 & 6 & +1 \\
\hline La Rioja & 312.719 & 0 & 1 & -1 \\
\hline $\begin{array}{c}\text { C. } \\
\text { Valenciana }\end{array}$ & 4.948.411 & 8 & 12 & -4 \\
\hline Otros países & - & 13 & 13 & - \\
\hline España & 46.530 .000 & 126 & 126 & - \\
\hline
\end{tabular}

Fuente: Elaboración propia. 
Indagar sobre este aspecto, sus causas y posibles soluciones, nos parece esencial y por ello se incluyeron en el cuestionario unas preguntas para intentar aclarar los motivos de la sobrerrepresentación e infrarrepresentación de los originarios de unas comunidades autónomas sobre otras, si se considera relevante el fenómeno y por qué, y alguna posible solución al asunto.

INFLUENCIA DEL ORIGEN GEOGRÁFICO SOBRE EL DESARROLLO DE LOS ROLES DE LOS ACE

Llegados a este punto, se indagó sobre si dicho origen geográfico podía tener influencia en el ejercicio de los diversos roles expresados anteriormente (véase Tabla 4). Los resultados sugieren que los ACE dan una importancia relativamente baja a la relación existente entre origen del miembro y la mejoría en la función o rol desempeñado. En efecto, en ningún caso supera el $50 \%$ aquellos que indican que esa relación podría mejorar su rol de garantes de la imparcialidad $(45,1 \%)$, facilitadores y mediación entre grupos $(41,2 \%)$ y de ideación y formulación de políticas $(33,3 \%)$, mientras que son muchos menos los que plantean que dicha relación mejoraría el ejercicio del rol partidista $(2,9 \%)$, de patrocinio de intereses $(10,6 \%)$, así como el de técnico ligado a la experticia $(17,6)$ y de expertos legales $(13,7 \%)$. Estos resultados son coherentes con la escasa simpatía que, a tenor de las respuestas abiertas, suscita el asociar criterios geográficos a las pruebas de selección en los altos cuerpos de la función pública del Estado, y que además se ve confirmada con los resultados extraídos de las entrevistas en profundidad. En efecto, algunos de los entrevistados no consideran que el asunto tenga mayor peso estratégico (Entrevista Sánchez-Beato), habida cuenta que los altos funcionarios incorporan una visión de Estado. En dicha entrevista se expresa que no se cree que un alto funcionario, por haber nacido en un lugar, tenga que desplegar una mayor sensibilidad hacia los temas relacionados con el mismo en su trabajo y que, en caso de que esa sensibilidad existiera, hay tantos factores aleatorios intervinientes que no la hacen operativa; por ejemplo: que el puesto ocupado esté relacionado con el tema y que la resolución del asunto solo dependa de esa persona. Otros entrevistados (por ejemplo, Entrevista Ferrándiz) le otorgan una importancia menor, y subordinada a otros temas más relevantes, pues a su juicio el asunto no se encuentra en la agenda política y existen aspectos sustantivos a desarrollar en el EBEP; por otra parte, en caso de activarse una iniciativa para modificar el sistema selectivo con el fin de mejorar la procedencia geográfica, los cuerpos reaccionarían y la frenarían. También se señala el impacto que sobre el principio de igualdad tendría esa posible discriminación positiva y la posibilidad de desventaja para la AGE, ya 
que las comunidades autónomas no lo aplican y algunas disponen de administración propia potente e incluso internacionalizada.

Tabla 4: ¿Facilita el origen geográfico el ejercicio de los roles con dimensión intergubernamental? Porcentajes

\begin{tabular}{ccc} 
Roles & $\begin{array}{c}\text { Origen } \\
\text { geográfico } \\
\text { facilita... }\end{array}$ & $\begin{array}{c}\text { General } \\
\text { anterior }\end{array}$ \\
\hline El rol técnico de expertos que ejercen una competencia & 17,6 & 89,2 \\
El rol de patrocinio de intereses & 10,8 & 5,9 \\
El rol de agente (broker), que negocia intereses diferentes & 17,6 & 15,7 \\
El rol de facilitadores, que median entre intereses de grupos & 41,2 & 52 \\
El rol partidista, que defiende una posición política bien & 2,9 & 2,9 \\
clara & 33,3 & 71,6 \\
El rol de ideadores y formuladores de nuevos programas & 45,1 & 87,3 \\
El rol de garante de la imparcialidad del Estado & 13,7 & 68,6 \\
El rol de expertos legales & 26,5 & 42,2 \\
El rol de defensor cívico que protege los derechos de la co- & & 1 \\
lectividad & 21,6 & $1981)$. \\
Otro & Rockman &
\end{tabular}

Y finalmente, y buscando concretar los ámbitos en que se sustancia la participación intergubernamental de las funciones que desarrollan los ACE, se les solicitó que seńalasen las opciones pertinentes de acuerdo con la experiencia de cada cual en el cuerpo (véase Tabla 5). Se buscaba destacar el espacio orgánico y funcional de cooperación existente en España y la contribución a su funcionamiento por parte de los ACE. Las respuestas sugieren el compromiso del cuerpo con la gobernanza multinivel del Estado. Su participación en asuntos intergubernamentales o con contenido intergubernamental se muestra especialmente clara e influyente sobre el colectivo de los políticos, ya sea en la elaboración de respuestas a preguntas parlamentarias $(63,4 \%)$, o en la coelaboración de actos normativos $(61,4 \%)$, o directamente en tareas de asesoramiento (43,6\%) ; también es muy relevante en lo relativo a la gestión de las políticas públicas, pues un porcentaje significativo dice haber participado en la implantación de las mismas con impacto intergubernamental $(57,4 \%)$, o en su evaluación $(41,6 \%)$. Aunque de manera no mayoritaria, también es muy frecuente su participación en las conferencias sectoriales $(46,5 \%)$ y en las conferencias bilaterales $(35,6 \%)$. En las respuestas a la pregunta abierta se proporcionó una de las claves para comprender la importante influencia de los altos cuerpos sobre los políticos en asuntos intergubernamentales: 
Los funcionarios deberíamos quedarnos en un nivel técnico y neutral. El problema es que, en ocasiones, la preparación de nuestros políticos es tan nefasta que la aportación de los funcionarios se convierte en más importante y vinculante. Eso, evidentemente, varía según el gobierno y la preparación de sus miembros.

Tabla 5: Dimensiones en que se sustancia la participación intergubernamental de los ACE. Porcentajes

Dimensiones

He participado en conferencias sectoriales o en sus órganos preparatorios 46,5

He participado en conferencias bilaterales o en sus órganos preparatorios

He participado en la redacción de respuestas parlamentarias con contenido intergubernamental

He asesorado a órganos políticos sobre asuntos intergubernamentales

He participado en la elaboración de actos normativos con impacto intergubernamental

He participado en la implantación de normativa con impacto intergubernamental

He participado en la evaluación de políticas públicas intergubernamenta- $\quad$ 41,6 les

Otro

Fuente: Elaboración propia.

CAUSAS DE LA SOBRE E INFRARREPRESENTACIÓN DE LOS ORIGINARIOS DE DETERMINADAS COMUNIDADES AUTÓNOMAS

Teniendo en cuenta los datos anteriores, se aprovechó el trabajo empírico para preguntar a los ACE su parecer sobre la etiología que conduce a esos resultados (véase Tabla 6 ).

En primer lugar, se interrogó por las causas de que, de acuerdo con los estudios sobre el origen geográfico de los ACE, se haya verificado una fuerte sobrerrepresentación de los nacidos en la Comunidad de Madrid y, aunque más tenue, de los originarios de Castilla y León y Aragón; y simultáneamente una infrarrepresentación de los nacidos en Cataluña, o Extremadura, por ejemplo. 
Tabla 6: Causas de la sobrerrepresentación en el cuerpo de ACE de originarios de algunas comunidades autónomas (Por ejemplo, Madrid, Castilla y León y Aragón). Porcentajes

Causas

No existen opciones alternativas a la administración pública, o tienen 22,5 tamaño reducido como salida profesional

Son las comunidades autónomas con mayor identificación ciudadana con el 26,5 Estado

Los preparadores de los procesos selectivos se encuentran en esas 67,6 comunidades autónomas

Es donde se ubican los centros de formación superior con titulación más adecuadas al cuerpo de ACE

Reproducción profesional de otros funcionarios (los hijos de los funcionarios se hacen funcionarios)

No disponen de una administración autonómica amplia y diversificada que oferte puestos atractivos similares a los ACE

Fuente: Elaboración propia.

Respecto de las causas de la sobrerrepresentación, despuntaron dos posibilidades: que los preparadores de los procesos selectivos se encuentran mayoritariamente en las provincias sobrerrepresentadas, lo que facilitaría su preparación a los originarios de las mismas (67,6\% de las respuestas) y la reproducción profesional de padres funcionarios, cuyos hijos también lo serían por tradición familiar (49\%). Sin embargo, hay que constatar que algunas de las causas previsibles no han recibido el apoyo esperable, como por ejemplo que no existen opciones alternativas a la administración pública, o tuvieran escaso tamańo, como salida profesional (22,5\%); que son las comunidades autónomas con mayor identificación ciudadana con el Estado (26,5\%); ser la sede de una institución de educación superior con titulaciones adecuadas $(24,5 \%)$ o no disponer de una administración autonómica amplia y diversificada que oferte puestos similares a los de ACE (19,6\%). También se constata un apoyo relevante a la opción "Otros" $(22,5 \%)$, por lo que en este caso la respuesta a la pregunta abierta sobre el particular tiene especial interés, tanto numéricamente como cualitativamente, así como las entrevistas realizadas.

Las respuestas a la pregunta abierta insisten en varios fenómenos. Se destaca la importancia de la cultura familiar-profesional, ya que permite estar familiarizado con el sistema de acceso, lo que es esencial para impulsar vocaciones y presentarse a las pruebas con visos de éxito. Se alude a causas organizativas (bajas retribuciones y poco interés por los asuntos territoriales) como impedimento para anclar a efectivos en el territorio que después 
puedan servir de escaparate y efecto llamada en su lugar de asentamiento. Se insiste en la relevancia de tener preparadores del cuerpo cerca para la preparación exitosa de las pruebas, así como un tejido universitario con tradición en las titulaciones más próximas a los temarios y funciones de los ACE. También se alude al problema histórico que España ha tenido de movilidad geográfica por causas laborales y excesivo apego al terruño de buena parte de la juventud, aspecto reforzado por la aparición de administraciones autonómicas que han frenado el trasiego de funcionarios públicos por todo el Estado y ofrecido puestos de mayor cercanía que los ofertados por la AGE. Finalmente, de las respuestas se deriva un fuerte y generalizado rechazo a introducir criterios o cupos geográficos en las pruebas de selección, pues según la opinión común de las respuestas alterarían los principios constitucionales de igualdad, mérito y capacidad.

Respecto de las causas de la infrarrepresentación (véase Tabla 7), aunque los resultados tampoco son concluyentes, los encuestados se decantaron por dar mayor importancia a disponer de una administración pública autonómica amplia y diversificada que oferta puestos similares a los de ACE $(53,9 \%)$ y no disponer de preparadores adecuados para este tipo de proceso selectivo $(45,1 \%)$. También se apuntaron con relativa fuerza motivos históricos $(37,3 \%)$, la baja identificación ciudadana en esos territorios con el Estado $(32,4 \%)$ o disponer de sectores productivos alternativos $(27,5 \%)$. No se da una gran importancia a la opción que planteaba no disponer de centros de formación superior con titulaciones adecuadas al cuerpo de $\mathrm{ACE}(8,8 \%)$, probablemente porque la extensión del mapa universitario de los últimos años y creación de múltiples centros universitarios públicos y privados ha mitigado su efecto. Y, por otra parte, también aparece con relativa fuerza la opción "Otros" (19,6\%). 
Tabla 7: Causas de la infrarrepresentación en el cuerpo de ACE de originarios de algunas comunidades autónomas (Por ejemplo, Cataluńa, Extremadura). Porcentajes

Causas

Disponen de sectores productivos alternativos a la administración pública

Son las comunidades autónomas con menor identificación ciudadana con el

Estado

Motivos históricos

No disponen de preparadores adecuados para este tipo de proceso selectivo

Disponen de una administración autonómica amplia y diversificada que oferta 53,9 puestos atractivos similares a los ACE

No disponen de centros de formación superior con titulaciones adecuadas al cuerpo de ACE

Fuente: Elaboración propia.

Los datos procedentes de las entrevistas permiten enriquecer las explicaciones. Alguno de ellos (Entrevista Sánchez-Beato) apunta, como causas de la sobre e infrarrepresentación, a la falta de cultura de función pública en algunas comunidades autónomas por diferentes aspectos (existencia o no de otras opciones profesionales, escasez o abundancia histórica de opositores, etc.). Otros enfatizan en tres aspectos: la necesidad de conseguir trabajo, las alternativas existentes en el territorio, junto a un marcado localismo que impulsa a los ciudadanos a querer quedarse en su lugar de origen y que a veces se ve facilitado por la confección de los temarios y la valoración de idiomas propios, en perjuicio del principio de igualdad (Entrevista Ferrándiz). Finalmente, Cassese señalaba como factor explicativo la existencia de diferentes culturas o filosofías prevalentes en el caso italiano con influencia en el acceso al empleo público del Estado. En efecto, Cassese expresa que en Italia hay dos espacios con dos subculturas o prefilosofías distintas, que plantean mentalidades, vocaciones y preparaciones diversas: el sur, con una prefilosofía idealista, bajo desarrollo industrial y de donde proceden altos porcentajes de empleados públicos; y el norte, con una prefilosofía pragmática, con gusto por la empiria y donde la atracción del empleo público es menor o marginal. En su entrevista, Cassese relaciona directamente el grado de desarrollo económico con el deseo (o no) de acceso a la función pública e indica que los datos no han cambiado sustancialmente desde el año 1977 en que realizó estudios sobre el particular (Cassese 1977). Literalmente cita que "en las regiones con mayor desarrollo económico, más atracción ejerce el mercado y menos la Administración, y al revés, en regiones con menor desarrollo económico menor es la atracción que ejerce el mercado y mayor la Administración”. 
También alude a que no es un caso particular de Italia y España, sino también de Francia y otros países, reseñando la parisinización de la alta función pública francesa y el desierto francés de la periferia. Con todo, no le preocupa a Cassese tanto la sobrerrepresentación de determinadas regiones o de la capital del Estado como que la alta función pública no represente al conjunto del país (Entrevista Cassese). Como contrapunto, en otra entrevista se aportan matices de carácter histórico, en que se menciona que la AGE puede ser vista en algunos territorios como algo ajeno y quizás hostil, pero también a la inversa, una parte de la alta función pública nacional veía con cierta antipatía y desconfianza el nacimiento de las administraciones y funciones públicas autonómicas, recelos mutuos que, aunque matizados por el tiempo, han seguido operando en la consciencia colectiva (Entrevista Baena).

En este caso, en las respuestas por parte de los ACE a la pregunta abierta se hizo mención de la necesidad de estudiar el asunto comunidad por comunidad, ya que en algunos casos, como ocurriría en las comunidades autónomas con fuertes hechos diferenciales, la infrarrepresentación puede estar asociada al (escaso) grado de identificación con la AGE y aspectos que facilitan el acceso en la administración de su propia comunidad (como la introducción del dominio de la lengua oficial propia en las pruebas de acceso), mientras que en otras sin esas peculiaridades quizás las causas radiquen en otras motivaciones, destacando la debilidad de la administración periférica del Estado, que en el cuerpo que tratamos determina que casi el $84 \%$ de los ACE en servicio activo se encuentren radicados en los servicios centrales ${ }^{3}$, factor reforzado por los procesos ya conocidos de existencia de más academias de preparadores, la reproducción familiar y la escasa movilidad histórica de la población española.

\section{¿ES IMPORTANTE DICHA SOBRE E INFRARREPRESENTACIÓN ENTÉRMINOS DE INCLUSIVIDAD GEOGRÁFICA DEL ESTADO?}

En el trabajo empírico se solicitó la opinión de los ACE respecto de la importancia de la procedencia geográfica de las personas que trabajan en los altos cuerpos de la AGE (ver Tabla 8). Los resultados muestran la división existente en el colectivo respecto del asunto, aspecto que ya había sido puesto de relieve previamente al tratar el interés del factor

3 En efecto, de los 982 funcionarios en servicio activo del Cuerpo Superior de Administradores Civiles del Estado, 824 (83,91\%) están destinados en Madrid, 79 en provincias $(8,044 \%)$ y $79(8,044 \%)$ en la Administración exterior (embajadas y organismos internacionales). Datos extraídos de http://www.inap.es/que-es-elcuerpo-superior-de-administradores-civiles-del-estado1 [20-07-2016]. En un acceso reciente (junio de 2019), no se han encontrado datos numéricos sobre los integrantes del cuerpo. 
geográfico desde las perspectivas de los roles que deben desarrollar los ACE. En el caso que nos ocupa, aunque no son desdeńables las respuestas otorgadas al reconocimiento de la importancia del origen geográfico de los altos funcionarios, ya fuera porque la Administración debe ser un espejo de la sociedad a la que sirve $(48 \%)$, o porque puede mejorar las relaciones de cooperación entre el Estado y las comunidades autónomas de procedencia $(42,2 \%)$, no se destacan en exceso de las partidarias de no darle trascendencia, ya sea por no considerar la procedencia geográfica relevante desde un punto de vista funcional $(39,2 \%)$, o representativo $(33,3 \%)$.

Tabla 8: ¿Es importante el origen geográfico de los altos funcionarios de la AGE?. Porcentajes

Respuesta

Sí, pues la Administración debe ser un espejo de la sociedad a la que sirve 48

Sí, pues los empleados públicos son un nexo privilegiado entre la política y la 27,5 sociedad

Sí, pues mantienen una especial sensibilidad a la hora de captar las necesidades de la comunidad autónoma de procedencia

Sí, pueden mejorar las relaciones de cooperación entre el Estado y su comunidad autónoma

No. No considero relevante desde el punto de vista funcional el origen geográfico de los empleados públicos

39,2

No. No considero relevante desde el punto de vista representativo el origen geográfico de los empleados públicos

Otro

Fuente: Elaboración propia.

Las respuestas a la pregunta abierta, ya reseñadas anteriormente, muestran en general desconfianza a favorecer cupos, de cualquier tipo, pero particularmente el territorial, en una función pública nacional que debe regirse por los criterios constitucionales ya citados. Lo mismo cabe agregar de la información obtenida de las entrevistas. Aunque algunas personas entrevistadas mostraron un cierto grado de comprensión ante el fenómeno defendiendo una "mirada favorable" hacia el área geográfica de procedencia por parte de los funcionarios en Italia (Entrevista Cassese) y que una mejor equirrepresentación podría redundar en mejorar la sensibilidad ante determinados problemas (Entrevista Ferrándiz), en términos generales no se concede al asunto una gran relevancia e incluso se entrevén peligros. De esta manera, se mantiene que, más que el aspecto territorial, se consideran importantes los aspectos sociales que afectan a la igualdad, tales como el déficit de representación social (infrarrepresentación de clases bajas y 
medias en la alta función pública y sobrerrepresentación de las bajas en los puestos de menor nivel orgánico y/o funcional (Entrevista Ferrándiz). Asimismo, y después de restar sentido a una mejor representación de los originarios de determinados territorios en una función pública que debe regirse por los criterios de igualdad, mérito, capacidad y publicidad, se alerta de que

allí donde se dan discriminaciones positivas a favor de etnias u otras minorías (por ejemplo, en los Balcanes), la OCDE ha verificado un deterioro de la calidad de las decisiones públicas; habida cuenta de que hay puestos reservados, la aplicación de baremos de exigencia tienen un impacto discutible (Entrevista Sánchez-Beato).

\section{CÓMO PODRÍA MEJORARSE LA “REPRESENTATIVIDAD” AUTONÓMICA EN LOS ACE}

Por otro lado, se obtuvieron datos sobre cómo, según los ACE, podría mejorarse la representatividad autonómica en el cuerpo para aquellas comunidades autónomas cuyos ciudadanos se encuentran infrarrepresentados en relación al peso poblacional relativo de las mismas en el conjunto del Estado (véase Tabla 9). La respuesta más destacada, con gran diferencia con el resto, fue la que aludía a intervenir en la fase de reclutamiento o atracción de candidatos a las pruebas, haciendo especial énfasis en las comunidades autónomas infrarrepresentadas (77,5\%), seguida a gran distancia por la realización de las pruebas de selección de manera territorializada en las diferentes comunidades autónomas (22,5\%). Sin embargo, fueron inapreciables quienes indicaron que mejoraría la situación mediante la modificación del contenido de las pruebas de selección, incluyendo más contenidos autonómicos $(5,9 \%)$ o a través de la reserva de cupos o cuotas a las comunidades autónomas de acuerdo con su peso demográfico (1\%). Muy significativo, comparativamente, fue el apoyo a "Otros" $(23,5 \%)$, lo que obliga a analizar cuidadosamente las respuestas a la pregunta abierta final de este epígrafe, así como las entrevistas realizadas.

Las respuestas a la pregunta abierta incluyen nuevas posibilidades. Por una parte, se plantea la posibilidad de anclar la ACE en la estructura periférica del Estado, con mejores condiciones profesionales y retributivas, lo que permitiría dar a conocer el cuerpo y difundir con un programa específico las funciones que realiza; por otra, la incentivación del conocimiento de otras lenguas españolas además del castellano. Y finalmente, mejorar la difusión de la oferta de empleo público, potenciar el sistema de becas y la comunicación y colaboración con las escuelas de función pública y universidades autonómicas. En esta línea, coincidente con recientes 
publicaciones que dan cuenta de la preocupación por parte del colectivo de la selección de ACE y de directivos públicos (por ejemplo, Mapelli et al. 2017), es reveladora la siguiente aportación:

Resulta urgente mejorar los mecanismos para la difusión de la oferta de empleo público por parte de la DG de Función Pública; convocar y dotar adecuadamente becas para la preparación de los procesos selectivos al A1 para asegurar la representatividad social y geográfica de nuestra función pública superior; explorar todas las posibilidades que brinda la adaptación al espacio europeo de educación superior de nuestras titulaciones y las fórmulas de colaboración con las escuelas de función pública superior de la AGE.

Tabla 9: Cómo mejorar la representatividad en el cuerpo de ACE de las comunidades autónomas infrarrepresentadas. Porcentajes

Posible solución Mejorando el reclutamiento (atracción de candidatos) en las comunidades
autónomas menos representadas

Modificando el contenido de las pruebas de selección, incluyendo más contenidos autonómicos

Realizando las pruebas de selección en las comunidades autónomas

Reservando cupos o cuotas a las comunidades autónomas y ciudades autónomas de acuerdo con su peso demográfico

Otro:

Fuente: Elaboración propia.

Respecto de las entrevistas, se insiste con carácter general en la necesidad de intervenir antes en otros aspectos y no en los criterios que sustentan el proceso selectivo en la Administración. Se enfatiza en la posibilidad de mejorar la fase de reclutamiento, entendida como el proceso de atracción de ciudadanos a los procesos selectivos mediante una mejor difusión de la oferta de empleo público, en el establecimiento de un sistema de becas para ciudadanos con menos recursos que pudieran tener mayor sensibilidad territorial o impartiendo clases de apoyo en algunas comunidades autónomas (Entrevista Sánchez-Beato), lo que tendría un doble impacto: mitigaría el sesgo socioeconómico y también el territorial (Entrevista Ferrándiz). En la misma línea, y a pesar de expresar que antes de aplicar cupos territoriales hay que pasar por otras fases, se precisa que, para conseguir una democracia de calidad y una función pública en consonancia, se requiere intervenir en la cultura sociopolítica. En ese sentido, y aunque suele utilizarse la excusa de la tradición, esta debería cambiar, pues 
hay que atacar las diferentes barreras: educativas, socioeconómicas, territoriales y las propias del modelo de selección (las técnicas, que incorporan y perpetúan los sesgos). Plantearse de frente si esos sesgos también los produce el modelo de acceso. Para esto último, en el tema territorial, planteo realizar alianzas con universidades y escuelas territoriales, ofertar prácticas en la AGE relacionadas con esos centros de formación y para ciudadanos de esos territorios, proporcionar ayudas, etc. También es necesario cambiar la filosofía del modelo. En un modelo de competencias debe cambiar la manera de ver y gestionar el talento y las capacidades (Entrevista Arenilla).

También en esta última entrevista, se alude a la necesidad de mejorar el sistema de selección de los altos funcionarios y personal directivo mediante organizaciones independientes conectadas al Parlamento.

Las opiniones contrarias a los cupos territoriales son frecuentes e incluso amplían el foco a otras posibles discriminaciones positivas (de género, discapacidad, étnicas...) en algunos casos. Por ejemplo, en la entrevista con Baena se expresa prevención ante un "inmoderado carácter representativo socialmente de la función pública”. El entrevistado piensa que ese criterio, venido desde los Estados Unidos, fracasó y que él "formó parte del grupo de enterradores de esa idea”, pues fue objeto de análisis por un grupo en el Instituto Internacional de Ciencias Administrativas al que perteneció y se concluyó que no estaba justificado y que podría atentar contra el principio de igualdad de los ciudadanos.

Una cosa es que convenga favorecer la posibilidad de que cualquier ciudadano llegue a formar parte de un alto cuerpo, y otra que se esté dificultado o violentando la posibilidad de que ello suceda. A nadie se le impide, lo que hace falta es superar las pruebas, aunque se puede mejorar el reclutamiento y la preparación de las pruebas mediante centros públicos, privados y ayudas (Entrevista Baena).

Y es que para el Baena la fase de reclutamiento es tan importante o más que la de selección. Por el contrario, otro entrevistado, muestra una gran preocupación porque la función pública sea adecuadamente representativa de la sociedad, alertando contra lo que denomina "veto representativo". Además, en tanto juez constitucional italiano, ve posible incluir "acciones activas" con miras a aminorar la distancia entre la igualdad formal y sustancial del acceso de los ciudadanos a los empleos públicos (Entrevista Cassese). 
En otras entrevistas también se alude a la necesidad de mejorar lo relativo a las condiciones laborales de los empleados públicos de la AGE en el territorio. En la administración periférica de la AGE los niveles son inferiores a Madrid.

El candidato local puede pensar para qué hacer una oposición dura si le va a tocar viajar (conocer mundo) y cuando regrese a su tierra a lo máximo que podrá aspirar es a un nivel 26 o 28 (Director Provincial), puesto además muy quemado políticamente. Mejor prefieren, si quieren ser profetas en su tierra, prepararse las locales o autonómicas, que le permitirán llegar al cielo más rápidamente y sin casi viajar (Entrevista Ferrándiz).

En esta entrevista también se expresa la importancia de mejorar la movilidad interadministrativa denunciando la reciprocidad del cierre de las administraciones públicas territoriales para los procedentes de otras distintas, vía relaciones de puestos de trabajo (RPT).

\section{EL INTERÉS DE LA MOVILIDAD INTERADMINISTRATIVA}

Dada la relevancia que se otorga a la movilidad interadministrativa como instrumento de circulación del talento y de las élites administrativas, e igualmente como instrumento de cohesión y cooperación del Estado, se dedicaron varias preguntas a documentar el grado de conformidad de los ACE con la misma, así como sus posibilidades de mejora. Un primer exponente de la importancia que se otorgaba a la movilidad por parte de los ACE se obtuvo del estudio sobre el ciclo selectivo en la AGE, que fue dirigido por Ruano (2014) y publicado por el Instituto Nacional de Administración Pública.

En primer lugar, es importante constatar que la percepción general es que la movilidad interadministrativa no funciona bien en el Estado español $(78,5,6 \%$ de acuerdo o totalmente de acuerdo versus $10,7 \%$ en desacuerdo, totalmente en desacuerdo) (véase Gráfico 3). A pesar de ese mal funcionamiento, los ACE consideran que una movilidad interadministrativa perfeccionada permitiría una mejor integración del sistema políticoadministrativo $(64,8 \%$ versus $14,7 \%)$ y que debería jugar un papel esencial para mejorar la eficacia de las relaciones intergubernamentales $(65,8 \%$ versus $14,7 \%$ ). 
Gráfico 3: La movilidad interadministrativa en España

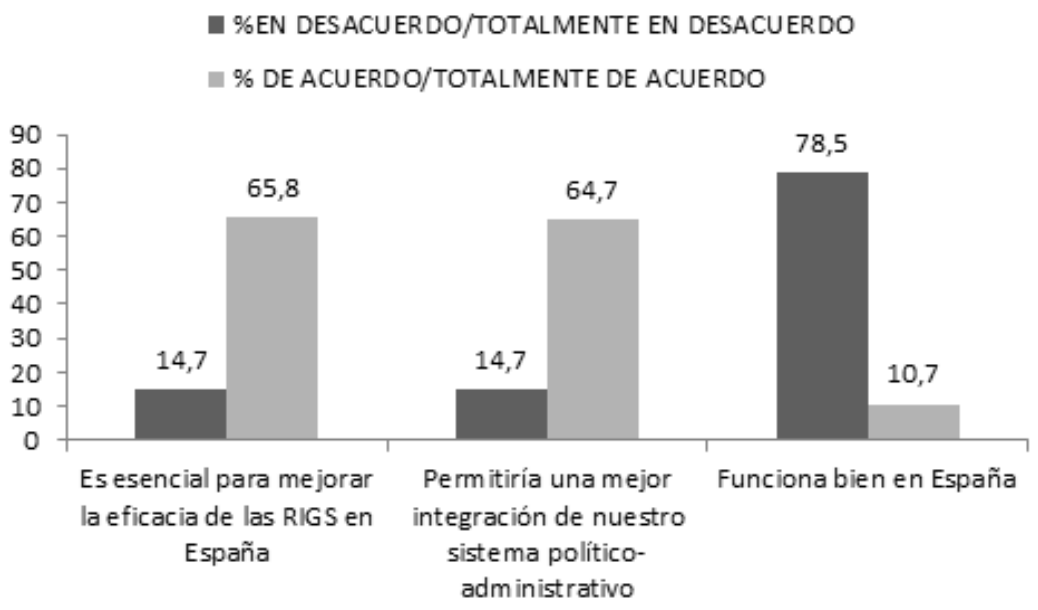

Fuente: Elaboración propia.

También se pronunciaron los ACE sobre la manera de mejorar la movilidad interadministrativa (ver Tabla 10), a la que, como se ha visto, se otorga gran interés para generar integración político-administrativa entre las diferentes administraciones del Estado. Cabe recordar que la movilidad entre diferentes administraciones está permitida por la normativa y que teóricamente podría ser posible con voluntad política, pero en la práctica se encuentra muy limitada habida cuenta de las escasas dotaciones asignadas y excesivas rigideces imputadas a las correspondientes RPT que deberían dar cuenta de la apertura de los puestos. Esto dicho, los ACE estiman que podría mejorarse la movilidad mediante el intercambio temporal de funcionarios $(67,6 \%)$, favoreciendo la ocupación de puestos apropiados en las diferentes administraciones a originarios de otras $(65,7 \%)$, favoreciendo la realización de prácticas formativas $(52,9 \%)$ o eliminando obstáculos legales $(41,2 \%)$. En cualquier caso, el porcentaje que estima que el sistema no debe cambiarse es nimio $(3,9 \%)$. 
Tabla 10: Cómo mejorar la movilidad interadministrativa. Porcentajes Posibles medidas

\begin{tabular}{cc}
\hline $\begin{array}{c}\text { Favoreciendo la ocupación de puestos apropiados de las } \\
\text { administraciones autonómicas a los ACE, y viceversa }\end{array}$ & $65,7 \%$ \\
$\begin{array}{r}\text { Favoreciendo el intercambio temporal de funcionarios entre } \\
\text { administraciones autonómicas y el Estado }\end{array}$ & $67,6 \%$ \\
$\begin{array}{r}\text { Favoreciendo la realización de prácticas de los funcionarios en formación } \\
\text { de la AGE en las administraciones autonómicas, y viceversa }\end{array}$ & $52,9 \%$ \\
Eliminando los obstáculos legales para favorecer la movilidad & $41,2 \%$ \\
administrativa & $3,9 \%$ \\
Otreo que funciona bien y no necesita cambiarse & $6,9 \%$
\end{tabular}

Fuente: Elaboración propia.

En las entrevistas también hubo abundantes referencias a la movilidad, abordando tanto las problemáticas que le afectaba como sus potencialidades. Respecto de los problemas, aun reconociendo que en el seno de la AGE existe gran movilidad, cada vez es más difícil darle contenido territorial, habida cuenta del limitado número de plazas que se ofertan por mor de la descentralización a favor de las comunidades autónomas (Entrevista Sánchez-Beato). Por otra parte, también se alude al déficit de movilidad entre AAPP, facilitada para los niveles altos y personal de libre designación, para los cuales se requieren contactos personales y respaldo político, y no para el resto de los empleados públicos profesionales, respecto de los cuales se realiza de facto un cierre recíproco de las AAPP para los foráneos vía RPT (Entrevista Ferrándiz). Arenilla redunda en la misma idea, pues la ley permite la movilidad interadministrativa y, de hecho, recuerda, (la entrevista tuvo lugar en enero de 2016) 5 ACE habían desembarcado en el Ayuntamiento de Madrid. Considera que en la AGE hay bastantes puestos abiertos a otras AAPP; pero no está seguro de que el grado de aceptación de los funcionarios del Estado sea similar en el caso de comunidades autónomas y entidades locales. De hecho, piensa que el EBEP ha modificado el asunto y reducido en la práctica dicha movilidad al limitarla a los puestos de libre designación (que son a los que pueden acceder realmente los $\mathrm{ACE}$ ), pues con el cese se obliga a volver a su puesto de origen. (Entrevista Arenilla).

Baena recordaba que esa movilidad interadministrativa sí fue tenida en cuenta en el momento de creación de las funciones públicas autonómicas y que de hecho varios TACs tuvieron una participación significativa en esos momentos fundacionales en comunidades autónomas como Andalucía, Murcia, La Rioja, Aragón y la Comunidad Valenciana. Sin embargo, no está dispuesto a sobrevalorar la simpatía con que las autoridades autonómicas acogían a los altos funcionarios del Estado, de manera que el tránsito de funcionarios o no se dio, o fue esporádico, o numéricamente 
poco importante. Estima que una de las causas de la mala colaboración entre administraciones es la práctica administrativa de no realizar la movilidad o convertirla en algo muy difícil. Y dice que es una práctica administrativa, ya que la ley lo permite y estima que es fundamental para el funcionamiento del sistema. Según su criterio, "no solo no sacan plazas o de manera muy insuficiente, sino que existe una enemistad clara hacia la movilidad" (Entrevista Baena). A la misma idea acude Cassese, señalando que, a pesar de las apariencias, la función pública no está abierta. Las comunidades autónomas han creado sus cuerpos replicando los del Estado y se han acantonado ahí. Debería mejorarse la movilidad mediante la apertura de los puestos, pero también creando un sistema de incentivos para favorecerla (ayudas al alquiler, traslado, etc.) (Entrevista Cassese).

Finalmente, y teniendo en cuenta que desde el punto de vista del proceso selectivo "la gran obsesión del modelo español radica en la profunda desconfianza en la decisión inicial que propicia el acceso, y una mayor confianza en la redistribución interna posterior", sorprende que después de varias décadas esa redistribución posterior no haya conseguido incorporar de manera integrada un buen elenco de puestos abiertos entre Estado y comunidades autónomas (Entrevista Pérez Cruz), lo que respalda la idea de Baena, anteriormente apuntada, de que una de las causas de la magra colaboración interadministrativa radica en la escasa movilidad existente entre las diferentes administraciones españolas.

\section{CONCLUSIONES}

En el presente estudio se explotan los frutos de una investigación empírica realizada sobre las funciones intergubernamentales de los ACE y la importancia del origen geográfico de sus miembros, causas de la infra y sobrerrepresentación de los ciudadanos procedentes de las diferentes comunidades autónomas en la AGE, usando como instrumento de análisis el cuerpo de ACE. Entre los resultados extraídos cabe destacar los siguientes aspectos:

1. Los estudios intergubernamentales que analizan la alta función pública en tanto instrumento relevante para conocer el funcionamiento de los estados proporcionan interesantes orientaciones para analizar la cohesión e inclusividad de los mismos, tanto desde una perspectiva explicativa como heurística.

2. Los ACE colaboran decisivamente con los políticos en la confección de decisiones públicas e implantación de las mismas con impacto autonómico, lo que permite confirmar la existencia del "veto 
decisorio" y "paralizante" con que Baena (1988) caracterizaba a la alta función pública.

3. Teniendo como referente interpretativo la categorización de los roles político-administrativos elaborada por Aberbach, Putnam y Rockman (1981) y su importancia en los procesos decisorios, se concretó que los ACE en el ejercicio de sus funciones se identifican fundamentalmente con el rol del técnico que ejerce una competencia $(89,2 \%)$, el de garante de la imparcialidad del Estado (87,3\%), el de ideadores y formuladores de nuevos programas $(71,6 \%)$ y el de expertos legales $(68,6 \%)$. Los roles que exigen una toma de postura de carácter partidario o vinculada a intereses particulares tienen escaso apoyo. A grandes rasgos se concluye que el colectivo estudiado interpreta sus expectativas de actuación en términos ligados a la competencia técnica y jurídica, pero también respecto de los valores básicos del servicio público (neutralidad e imparcialidad), sin despreciar aspectos creativos (rol de ideadores y formuladores) junto a los que facilitan la interacción (facilitadores y mediadores). Y también se sugiere que el origen geográfico de los ACE no afecta de manera determinante al ejercicio de los roles citados por dicho colectivo ni es un aspecto estratégico en este momento a tener en cuenta cuando todavía queda por desarrollar parte sustantiva del EBEP.

4. Los ACE en el ejercicio de sus funciones tienen un claro compromiso con la gobernanza multinivel del Estado español, lo que se sustancia en su participación en espacios orgánicos y funcionales de cooperación intergubernamental. Funcionalmente, el desempeño intergubernamental se concreta con fuerza en la elaboración de respuestas parlamentarias, coelaboración de actos normativos, gestión e implantación de políticas públicas y, significativamente, aunque en menor medida, participando en los órganos sectoriales y bilaterales de cooperación/coordinación entre Estado y comunidades autónomas.

5. Habida cuenta de la importancia que tiene la alta función pública en la conformación de la cultura y liderazgo políticos, así como por su estrecha relación con las élites públicas y privadas del país, es interesante conocer datos de carácter sociológico sobre ella, entre los que destacan los relativos al origen geográfico. Como otras investigaciones trasladan la preocupación de una importante sobrerrepresentación de altos funcionarios originarios de comunidades autónomas concretas sobre otras, sin que la situación se haya modificado significativamente desde los años setenta del siglo pasado, parece interesante conocer la percepción de los ACE sobre el particular. Respecto de las causas de la sobrerrepresentación, 
se destacó en la encuesta la importancia de la ubicación geográfica de los preparadores y la reproducción profesional entre padres e hijos por tradición familiar. Esos aspectos fueron respaldados por las entrevistas, donde también se aludió a la necesidad de mejorar las condiciones laborales de los ACE en el territorio, la cultura pública de la comunidad autónoma y la existencia de sectores productivos alternativos. Curiosamente, no se otorga gran importancia a tener cerca centros formativos de educación superior que oferten titulaciones apropiadas, aspecto históricamente realzado por la literatura. En lo relativo a la infrarrepresentación, la encuesta plantea un apoyo mayoritario a la opción que integraba la importancia de disponer de una administración pública autonómica amplia y diversificada que oferta puestos similares a los de ACE, y un apoyo muy significativo a la de no disponer de preparadores adecuados para este tipo de proceso selectivo, motivos históricos, la baja identificación ciudadana en esos territorios con el Estado, o disponer de sectores productivos alternativos. En las entrevistas, se refuerza lo expresado en la encuesta y se incluyen aspectos nuevos, como por ejemplo la relevancia del localismo y falta histórica de movilidad laboral en determinados territorios o la muy sugerente explicación expresada por Cassese fundada en la existencia de diferentes subculturas territoriales, con mayor gusto hacia la función pública según su grado de idealismo y pragmatismo.

6. Interrogados los ACE sobre la importancia de la procedencia geográfica de los altos funcionarios de la AGE, las respuestas muestran división. Sin ser mayoritarias, son significativas las respuestas que otorgan interés a dicha procedencia por motivos representativos (la función pública debe reflejar la realidad social), porque puede mejorar las relaciones de cooperación o por la posibilidad, señalada en las entrevistas, de encontrar una mirada favorable a los intereses de su comunidad autónoma. Pero con casi idéntica fuerza aparecen las respuestas a la encuesta que no consideran la procedencia geográfica del funcionario público importante a efectos funcionales o representativos. Las respuestas abiertas a la encuesta y las entrevistas señalan obsesivamente la oposición a los cupos territoriales, por su impacto en la uniformidad e igualdad del sistema selectivo, y la necesidad de explorar otras vías, fundamentalmente mediante el reclutamiento, realización de pruebas descentralizadas, ayudas a la preparación y convenios con instituciones formativas. Estas posibilidades contribuirían a mitigar no solo el sesgo territorial sino también el socioeconómico en el acceso. Tampoco faltan opiniones ambiciosas que indican la necesidad de cambiar la filosofía del modelo selectivo, hacia uno basado en competencias, así como de 
mejorar el sistema de selección de los altos funcionarios y personal directivo mediante organizaciones independientes conectadas al Parlamento.

7. Los encuestados consideran adecuados los principios sobre los que reposa el proceso selectivo que les permitió el acceso al cuerpo, de manera muy mayoritaria $(74,5 \%)$ frente a un escaso porcentaje que defiende lo contrario (5,9\%), resultados coherentes con los publicados en Ruano (2014). Si acaso, sin respaldo mayoritario, pero sí significativo, se plantea la posibilidad de su enriquecimiento para incluir en mayor medida la diversidad social y favorecer una mejor representación de todas las clases sociales $(38,2 \%)$ así como para incorporar en mayor medida la diversidad territorial $(9,8 \%)$. Las entrevistas en profundidad, en general, respaldan los resultados de la encuesta, aunque en algunos casos traslucen escepticismo con el conformismo general o incluso proponen reformas de calado para afrontar, entre otros aspectos, todos los sesgos relativos al sistema selectivo ya radiquen en aspectos socioeconómicos, étnicos, territoriales o discapacidades. Otros entrevistados plantearon la necesidad de que la AGE no pierda la capilaridad en el territorio desde un punto de vista funcional e institucional y que la función pública del Estado, con independencia de su origen y donde se encuentre ubicada, sea representativa del conjunto del país.

8. Finalmente, y habida cuenta de la importancia que se otorga a la movilidad interadministrativa para un funcionamiento más integrado del Estado, se dedicaron varias preguntas al asunto. Los encuestados expresaron su conformidad con que dicha movilidad es esencial para mejorar la eficacia de las relaciones intergubernamentales en España y que la misma permitiría una mejor integración del sistema político-administrativo. Sin embargo, el 78,5\% de ellos expresa desacuerdo con su funcionamiento y solo un 3,9\% indica que no debería cambiar. En las entrevistas se traslada la escasa simpatía que las autoridades autonómicas tienen por la movilidad interadministrativa y la paradoja de que, a pesar de su permisión por la normativa, los usos administrativos han tendido a cerrarla a través de las RPT. Además de modificar esas malas prácticas, se señalan formas de mejorar la movilidad: el intercambio temporal de funcionarios, favoreciendo la ocupación de puestos apropiados en las diferentes administraciones a originarios de otras, favoreciendo la realización de prácticas formativas y eliminando obstáculos legales. 


\section{REFERENCIAS}

AAVV. (2014). Administradores civiles del Estado (1964-2014). 50 años de servicio público: 50 protagonistas. Madrid: Asociación del Cuerpo Superior de Administradores Civiles del Estado, Instituto Nacional de Administración Pública.

Aberbach, J., Putnam, R. y Rockman, B. (1981). Bureaucrats and politicians in western democracies. Cambridge: Harvard University Press.

Agranoff, R. (1991). Marcos para el análisis comparado de las relaciones intergubernamentales. Papeles de trabajo del Instituto Ortega y Gasset $n^{\circ}$ 291. Serie Gobierno y Administración. Madrid: Instituto Ortega y Gasset.

(1997). Las relaciones y la gestión intergubernamentales. en Bañón R. y Carrillo, E. (Eds.), La nueva administración pública. Madrid: Alianza Editorial.

Álvarez, J. (1980). El origen geográfico de los funcionarios españoles. Madrid: Instituto Nacional de Administración Pública.

Anderson, W. (1960). Intergovernmental relations in review. Minneapolis: University of Minnesota Press.

Arbós, X., Colino, C., García M. J. y Parrado, S. (Coord.). (2009). Las relaciones intergubernamentales en el Estado autonómico. La posición de los actores. Barcelona: Institut d'Estudis Autonómics.

Baena del Alcázar, M (1988). Curso de la Ciencia de la Administración, Vol. I, 2a Ed. Madrid: Tecnos.

Cassese, S. (1977). Questione amministrativa e questione meridionale. Domensioni e reclutamiento della burocracia dall'Unita ad oggi. Milán: Giuffrè.

Cho, C. L., (2007). Understanding intergovernmental coercion: Explaining American State Administrators' perceptions of national regulatory influences. International Review of Public Administration, 12 (1), 51-62.

Colino, C., (2012). Las relaciones intergubernamentales en España: un estado de la cuestión y algunas consideraciones en perspectiva comparada. En Colino, C., Ferrín, M. y León, S. (Eds.), La práctica 
de la cooperación intergubernamental en España. Madrid: Centro de Estudios Políticos y Constitucionales.

Crespo González, J. (2015a). La función pública ante un escenario de gobernanza multinivel: Crisis y reinvención. En Crespo González, J., (Dir.), Crisis y reinvención de la función pública ante un escenario de gobernanza multinivel. Madrid: INAP.

(2015b). La centralidad del estudio de la función pública en un escenario de gobernanza multinivel en crisis. En Crespo González, J., (Dir.), Crisis y reinvención de la función pública ante un escenario de gobernanza multinivel. Madrid: INAP.

. (2015c). Pluralismo geográfico del origen de los altos funcionarios de la Administración general del Estado. En González García, E. et al. (Coords.), Mundos emergentes: cambios, conflictos y expectativas. Toledo: Asociación Castellano-Manchega de Sociología.

. (2017), Coordinación intergubernamental en España vista por la alta función pública del Estado. Política y Sociedad, 54, 481-508.

Del Pino, E. y Colino, C. (2021). ¿Qué sabemos sobre cómo reformar la administración?: Contenidos, capacidad y trayectorias. En Del Pino, E. y Subirats, J. (Eds.), Repensando la Administración ante los nuevos riesgos sociales y globales. Madrid: INAP.

Mapelli Marchena, C. et al. (2017). Nuevos tiempos para la función pública. Propuestas para atraer y desarrollar el talento en la Administración General del Estado. Madrid: INAP.

Parry, R. (2004). The civil service and intergovernmental relations. Public Policy and Administration, 19 (2), 50-63.

(2012). The civil service and Intergovernmental Relations in the Post-devolution UK. The British Journal of Politics and International Relations, 14, 285-302.

Peters, B. G. (2008). The civil service and governing: reclaiming the center. International Review of Public Administration, 13 (2), 1-12.

Ruano de la Fuente, J. M. (Dir.), Crespo González, J., y Polo Villar, C., (2014). Los funcionarios ante el espejo. Análisis del ciclo de selección de personal de la Administración General del Estado. Madrid: INAP. 
Schnabel, J., (2020). Managing interdependencies in federal systems: Intergovernmental councils and the making of public policy. Nueva York: Palgrave Macmillan.

Stein, J. W. (1984). Improving intergovernmental relations through public service careerism. Journal of Policy Analysis and Management, 3 (3), 453-457.

Valdivieso, R. (1996). La carrera diplomática en España (1939-1990). Madrid: Biblioteca Diplomática Española.

Verkuil, P., (2015). Deprofessionalizing State Governments: The rise of public art-will employment. Public Administration Review, 75 (2), 188-189.

Wright, D (1978). Del federalismo a las relaciones intergubernamentales en los Estados Unidos de América. Una nueva perspectiva de la actuación recíproca entre el gobierno nacional, estatal y local. Revista de Estudios Políticos, 6, 5-28.

. (1997). Para entender las relaciones intergubernamentales.

México: Fondo de Cultura Económica.

\section{ENTREVISTAS}

Arenilla Sáez, Manuel. Entrevista realizada el 21 de enero de 2016.

Baena del Alcázar, Mariano. Entrevista realizada el 23 de enero de 2016.

Cassese, Sabino. Entrevista realizada el 3 de marzo de 2015.

Ferrándiz Manjavacas, Francisco. Entrevista realizada el 16 de abril de 2015.

Pérez de la Cruz, Jaime. Entrevista realizada el 30 de enero de 2013.

Sánchez-Beato Lacasa, Fernando. Entrevista realizada el 27 de marzo de 2015.

Recibido: 31-10-2020

Aceptación de la versión final: 15-12-2020 